\title{
Rumen microbial degradation of the top internode of maize Co125 and maize W401 observed by scanning electron microscopy
}

\author{
E Grenet, J Jamot, C Migné \\ INRA, Station de Recherches sur la Nutrition des Herbivores, Theix, \\ 63122 Saint-Genès-Champanelle, France
}

The objective of this trial was to examine the influence of the beginning of the appearance of lignin in the cell walls on the microbial rumen degradation.

Two lines of maize differing widely in their stem cell wall digestibility, Co125 and W401, were grown in a greenhouse and harvested $5 \mathrm{~d}$ after anthesis. The internode from the top of the stem was divided into 3 parts: the bottom, the middle and the top. This internode was chosen because it contains, at the bottom, the meristems with young cells not yet differentiated and, at the top, the various tissues differentiated. Lignin is present in the cell walls of the supporting tissues and the vascular tissues. The higher one goes along this internode, the greater the age and the higher the extent of lignification (Joseleau and Barnoud, 1975).

The dry matter disappearance in the rumen of the different parts of the internodes was measured in situ and accounted for 72,73 and $87 \%$ respectively for the top, the middle and the bottom of the upper internode from maize $\mathrm{Co125}$ and for 61,56 and $84 \%$ for the top, the middle and the bottom of the upper internode of maize W401, respectively.

Observations before and after degradation in the rumen of the top and the bottom of the upper internode of Co125 and W401 were made using light and scanning electron microscopy. The internode samples stayed in the rumen inside nylon bags for $4,8,24$ and $48 \mathrm{~h}$ and were prepared for scanning electron microscopy as previously described (Grenet and Barry, 1988). The results showed that the cell walls were thinner for both maize types in the bottom than in the top of the internode: the parenchyma cells differed from the fibres and the sclerenchyma cells by their size (they are larger) but all had thin walls in the bottom. The general aspect of the tissues from the bottom is soft. The lignified cell walls as evidenced by acid phloroglucinol and Maüle reactant were localized in the xylem of the bottom and extended to the fibres and the sclerenchyma in the top for both maize types. The bacterial colonization was abundant $4 \mathrm{~h}$ after introduction in the rumen, particularly in the bottom, and fungal spores fixed on the tissues were observed. Cellwall degradation began in the parenchyma and the phloem from the bottom of Co125 at this stage. Eight hours was necessary for the appearance of cell-wall degradation in the parenchyma from the tops. In the bottom of Co125 the vascular bundles were separated due to the disappearance of the surrounding tissues. At this stage the xylem vessels and some fibres were the only remaining tissues from the bottom of maize C0125. For the bottom of W401 such a high degree of degradation is obtained after $24 \mathrm{~h}$. The top of W401 resisted for $48 \mathrm{~h}$.

These results show that the apical internode is a good model to evidence the influence of lignin in cell-wall degradation. When the different tissues of the stem are differentiated, they show a decreasing susceptibility to rumen microbial degradation in the following order: phloem $>$ parenchyma $>$ sclerenchyma $>$ fibres $>$ vessels.

Grenet E, Barry P (1988) Anim Feed Sci Technol 19, 25-31

Joseleau JP, Barnoud F (1975) Phytochem 14, 71-75 